\title{
Tradisi Lisan Yogyakarta: Narasi dan Dokumentasi
}

\section{Sulistyowati}

Departemen Bahasa dan Sastra, Fakultas Ilmu Budaya, Universitas Gadjah Mada

Posel: lies_sulistyowati@ugm.ac.id

Tim Pengabdian kepada Masyarakat:

Daru Winarti, Sumarsih, Hendrokumoro, Djarot Heru Santosa, Ratun Untoro

\begin{abstract}
Yogyakarta is one of the provinces where people are still aware of their oral tradition. Oral tradition as a culture contains aspects of life of a society. Types of oral tradition are verbal oral traditions, half-oral traditions, and non-verbal (material) oral traditions. Narrating the tradition in written form becomes an effort in documentation, both in Javanese and Indonesian narratives. To translate it from the original language (Javanese) to Indonesian language creates some problems. The narrative script of the oral tradition still requires a lot of improvements in terms of language and the content of story. This research aims to train and assist people of Yogyakarta to write down their oral traditions. The activity specifically aims to create texts of oral tradition in Yogyakarta which can be published into a semi popular book. The program, then, should be followed up by cultural discussions on oral tradition in Yogyakarta.
\end{abstract}

Keywords: narrative, oral tradition, Yogyakarta

\begin{abstract}
Abstrak
Salah satu daerah yang masyarakatnya masih sadar akan kehadiran tradisi lisan adalah Yogyakarta. Tradisi lisan sebagai kebudayaan mengandung segala aspek kehidupan yang ada di masyarakat. Jenis kelompok tradisi lisan di antaranya tradisi lisan verbal, tradisi lisan setengah verbal, dan tradisi lisan nonverbal (material). Narasi tulis tradisi lisan menjadi sebuah upaya dalam dokumentasi, baik narasi berbahasa Jawa maupun bahasa Indonesia. Adanya alih bahasa dari bahasa Jawa ke bahasa Indonesia maupun sebaliknya membuat permasalahan baru muncul. Sebagian besar narasi yang terkumpul belum sepenuhnya dapat dianggap sebagai naskah karena masih memerlukan banyak perbaikan dalam segi bahasa ataupun isi cerita. Kegiatan Pengabdian kepada Masyarakat ini bertujuan untuk melatih dan mendampingi masyarakat Yogyakarta untuk menulis naskah tradisi lisan. Kegiatan pengabdian ini secara khusus bertujuan untuk menciptakan naskah tradisi lisan Yogyakarta yang dapat dipublikasikan menjadi buku semipopuler. Keberlanjutan program yang dapat dilakukan adalah terlaksananya diskusi budaya secara rutin tentang tradisi lisan Yogyakarta.
\end{abstract}

Kata Kunci: narasi, tradisi lisan, Yogyakarta

\section{Pendahuluan}

Tradisi lisan merupakan salah satu kebudayaan yang masih terjaga di masyarakat. Tradisi lisan sebagai kebudayaan mengandung segala aspek kehidupan yang ada di 
masyarakat. Ruang lingkup aspek kehidupan yang ada di tradisi lisan beragam jenisnya. Jenis kelompok tradisi lisan di antaranya tradisi lisan verbal, tradisi lisan setengah verbal, dan tradisi lisan nonverbal (material) (Jan Harold Brunvard dalam Suparno, 2018). Ketiga kelompok tradisi lisan tersebut berbentuk cerita rakyat, tarian rakyat, permainan rakyat, arsitektur rakyat, dan lain sebagainya. Salah satu daerah yang masyarakatnya masih sadar akan kehadiran tradisi lisan tersebut adalah Yogyakarta.

Sebelumnya telah dilakukan penyusunan data dan pemetaan tradisi lisan di Yogyakarta. Pendataan dan pemetaan tersebut terlaksana di Kabupaten Kulonprogo, Kabupaten Gunungkidul, Kota Yogykarta, dan Kabupaten Bantul. Beberapa data tradisi dinarasikan dengan menggunakan bahasa Jawa, namun banyak di antaranya menggunakan bahasa Indonesia. Adanya alih bahasa dari bahasa Jawa ke bahasa Indonesia ataupun sebaliknya membuat permasalahan baru muncul. Mayoritas narasi yang terkumpul belum sepenuhnya dapat dianggap sebagai naskah karena masih memerlukan banyak perbaikan dalam segi bahasa maupun isi cerita. Berikut ini merupakan salah satu contoh tradisi lisan berbentuk nyanyian yang dilakukan oleh dukun bayi Mbah Mar di Kulon Progo.

Adus banyu gege
Ilang syaraf sawane
Gari gelis gedhene
Lenggoh-lenggoh kaya godhong waluh
Riya-riya kaya godhong dlingo
Kudupe kaya kembang cempaka
Gedhene sapayung agung
Ben kena nggo ngayomi sanak sedulur
Mbanyu mili rejekine

Nyanyian tersebut dilantunkan oleh Mbah Mar saat memandikan bayi. Di dalam narasi tradisi lisan yang terkumpul dijelaskan maknanya sebagai berikut: (1) Banyu gege berarti banyu wayu (air kelapa muda hijau yang disiapkan untuk memandikan bayi) agar si bayi menjadi anak yang kebal (mempunyai imun yang baik); (2) Ilang syaraf sawane artinya menjauhkan anak dari sebangsa lelembut karena biasanya bayi baru lahir sangat peka terhadap makhluk gaib; (3) Gari gelis gedhene artinya harapan untuk si bayi agar tumbuh dan berkembang dengan baik serta cepat; (4) Lenggoh-lenggoh godhong waluh artinya harapan untuk si bayi agar kelak mempunyai hati yang lapang (seperti daun labu merah); (5) Riya-riya kaya godhong dlingo diartikan sebagai kesimbangan agar bayi atau anak berjalan tidak goyang dan tersandung; (6) Kudupe kaya kembang cempaka diartikan sebagai tolak bala; (7) Gedhene sapayung agung artinya hati yang luas tadi diharapkan sebagai payung agung agar tidak cepat emosi; dan (8) Ben kena nggo ngayomi sanak sedulur artinya harapannya kelak si bayi akan dapat mengayomi (melindungi, menolong, dan menaungi) saudara yang membutuhkan, dan mbanyu mili rejekine maksudnya agar si bayi mendapat rezeki yang berlimpah.

Tradisi lisan adus banyu gege tersebut mempunyai nilai kearifan lokal yang dapat diketahui oleh pembaca melalui narasi yang dibuat oleh penulis. Narasi tradisi lisan yang telah dibuat sebelumnya tentang adus banyu gege masih memerlukan perbaikan di bidang 
bahasa serta dokumentasi gambar pada peralatan yang digunakan saat memandikan bayi. Selain itu, narasi tradisi lisan dapat menjadi naskah yang baik apabila peserta dapat menggali informasi lebih jauh dari dukun bayi saat memandikan bayi.

Berdasarkan permasalahan tersebut dapat ditindaklanjuti dalam kegiatan pengabdian ini. Kegiatan pengabdian ini adalah penarasian dan dokumentasi teks tradisi lisan Yogyakarta. Kegiatan ini bertujuan untuk melatih dan mendampingi masyarakat Yogyakarta untuk menulis naskah tradisi lisan. Naskah yang dimaksud ialah sebuah narasi lengkap tentang suatu tradisi lisan di Yogyakarta. Masyarakat dapat mencari tradisi lisan yang belum pernah diangkat menjadi sebuah cerita ataupun sudah pernah diceritakan namun memiliki versi yang berbeda. Dalam menyusun naskah tradisi lisan diperlukan sebuah cerita yang mengandung informasi dan gambar sebagai realisasi cerita. Kegiatan pengabdian ini secara umum bertujuan untuk melestarikan dan mendokumentasikan tradisi lisan di Yogyakarta. Kegiatan pengabdian ini secara khusus bertujuan untuk menciptakan naskah tradisi lisan Yogyakarta yang dapat dipublikasikan menjadi buku semipopuler. Melalui kegiatan pengabdian ini diharapkan masyarakat menjadi lebih sadar akan pentingnya budaya menulis dan setidaknya mampu menuliskan kebudayaan yang ada di sekitarnya.

\section{Metode Pelaksanaan}

Pelaksaan program kegiatan pengabdian ini merupakan kegiatan pengabdian lanjutan yang berawal dari pendataan dan pemetaan tradisi lisan. Program kegiatan pengabdian ini berupa "Workshop Penulisan Naskah Tradisi Lisan Yogyakarta”. Kegiatan direalisasikan dalam bentuk workshop dan praktik pendataan tradisi lisan. Workshop merupakan program pendidikan tunggal yang dirancang untuk mengajarkan atau memperkenalkan peserta keterampilan praktis, teknis, atau ide-ide yang dapat digunakan dalam pekerjaan atau kehidupan sehari-hari. Pelaksanaan workshop tradisi lisan diikuti oleh 15-50 peserta. Kegiatan workshop diperlukan agar peserta memiliki bekal secara teoretis ataupun praktis dalam pemetaan tradisi lisan. Selain itu, kegiatan workshop juga menuntut keaktifan peserta dalam berpartisipasi. Keaktifan peserta diperlukan saat kegiatan tersebut karena peserta akan mengambil keputusan setelah diberi gambaran oleh tim pengabdian (narasumber) tentang penulisan naskah tradisi lisan. Peserta berperan penting dalam menggunakan metode pengumpulan tradisi lisan di lapangan. Tim pengabdian berperan untuk merangsang dan memotivasi peserta untuk mengeksplorasi data tradisi lisan melalui kumpulan daftar pertanyaan yang disediakan.

Dalam pelaksanaan program tersebut, tim pengabdian berkolaborasi dengan ahli kebudayaan dan masyarakat pegiat kebudayaan yang berada di Yogyakarta. Peran masyarakat pegiat kebudayaan adalah mengungkap dan menggali tradisi lisan yang ada di Yogyakarta, yang merepresentasikan daerah Gunungkidul, Sleman, Kulonprogo, Bantul, dan Yogyakarta. Selain itu, ahli kebudayaan berperan untuk mengkaji lebih dalam tentang makna filosofi yang ada pada tradisi lisan di Yogyakarta.

Kegiatan pendampingan penulisan naskah tradisi lisan Yogyakarta dilaksanakan dengan gambaran sebagai berikut.

1. Mengadakan seminar antara ahli kebudayaan dan masyarakat pegiat budaya. Partisipan, baik narasumber maupun peserta saling memberi informasi dan menjalin 
komunikasi mengenai jenis-jenis tradisi lisan yang ada di Yogyakarta.

2. Mengadakan praktik penulisan naskah tradisi lisan bagi masyarakat pegiat budaya. Peserta diberi gambaran narasi tradisi lisan yang telah terkumpul sebelumnya. Peserta menyiapkan pertanyaan-pertanyaan untuk menggali informasi yang pada gilirannya akan melengkapi dan memperkaya narasi tradisi lisan yang dipilihnya.

3. Mengadakan pendampingan dan evaluasi terhadap pelaksanaan kegiatan sehingga dapat mencapai tujuan yang diharapkan. Pendampingan peserta diperlukan untuk mengetahui seberapa jauh tanggung jawab peserta membuat naskah tradisi lisan. Pendampingan peserta juga diperlukan untuk mencari solusi dan membantu peserta apabila mengalami kesulitan saat membuat naskah tradisi lisan. Naskah tradisi lisan tersebut nantinya dapat direalisasikan menjadi buku ataupun bahan ajar.

Karena luasnya bidang tradisi lisan yang ada di Daerah Istimewa Yogyakarta, penyusunan data tradisi lisan yang hendak dipetakan pada kegiatan ini dibatasi pada kepercayaan rakyat (folk beliefs), di antaranya sistem pengobatan tradisional, gugon tuhon, cerita tentang makam keramat, hantu, legenda suatu tempat, makanan tradisional, batik, dan lain-lain. Hal-hal tersebut untuk saat ini dianggap merepresentasikan tradisi lisan yang ada di D.I.Y. Adapun rumusan kegiatan pelatihan penyusunan data bahan pemetaan tradisi lisan D.I.Y. adalah menggunakan pola 64 jam dengan rincian sebagai berikut. (1) Mengadakan pertemuan tatap muka I antara pembicara dan peserta pelatihan guna memberi pandangan dan gambaran mengenai jenis-jenis tradisi lisan, metode pengambilan data, dan pembuatan format kartu data. Pertemuan dilakukan selama 8 jam. (2) Peserta melakukan pengambilan data di lapangan sesuai dengan materi yang telah diterima pada saat pertemuan tatap muka I. Pengambilan data dilakukan selama 48 jam (12 hari dengan asumsi jam efektif 4 jam per hari) dengan bimbingan tim pengabdian/narasumber, baik pertemuan tatap muka maupun melalui media lain. (3) Mengadakan pertemuan tatap muka II. Pertemuan ini dilaksanakan dalam rangka mengompilasi data yang berhasil dikumpulkan oleh peserta agar siap saji dan siap dipetakan. Pelaksanaan kegiatan Pengabdian kepada Masyarakat tersebut dapat dijelaskan secara rinci pada pembahasan.

\section{Pembahasan}

Kegiatan pendataan dan pemetaan tradisi lisan yang telah dilakukan sebelumnya hanya sebagai awalan. Kegiatan "Workshop Penulisan Naskah Tradisi Lisan Yogyakarta” adalah kegiatan lanjutan yang diberikan kepada masyarakat pegiat budaya untuk menyempurnakan narasi tradisi lisan. Tradisi lisan yang telah terkumpul adalah sebanyak 32 narasi dari 29 peserta mencakup cerita rakyat, legenda, mitos, upacara adat, permainan, teater/drama, adat-istiadat, arsitektur, pakaian dan perhiasan, makanan dan minuman, dan obat-obatan tradisional. Melalui kegiatan ini masyarakat pegiat budaya mampu mengungkap lebih banyak tradisi lisan di Yogyakarta dan menggali lebih lanjut narasi tradisi lisan yang telah terkumpul.

Hasil pendataan dan pemetaan mampu mengumpulkan 32 tradisi lisan (Sulistyowati dkk., 2018). Tradisi lisan yang telah terkumpul terbagi menjadi tiga kelompok, yakni: 


\section{Tradisi Lisan Verbal}

Tradisi lisan verbal meliputi tradisi yang menceritakan tentang Cerita Rakyat Dusun Tunggul (Wiyana, 2018), Legenda Watu Dalang (Kunarso, 2018), Legenda Asal Mula Desa Katongan (Sustiawati, 2018), Brambang dan Bawang (Jayanti, 2018), Garebeg Besar Gunung Wijil Dusun Gudang (Widiyastuti, 2018), Legenda Makam Tahunan Desa Kaligintung Kecamatan Temon Kabupaten Kulon Progo (Mulbisah, 2018), Larangan dan Pujian (Mulbisah, 2018), Mitos Dusun Tlangu (Harningsih, 2018), Sumur Senggot: Kearifan Lokal Untuk Menjaga Sumber Mata Air (Harningsih, 2018), Legenda Pelus Raksasa (Istiqomah, 2018),

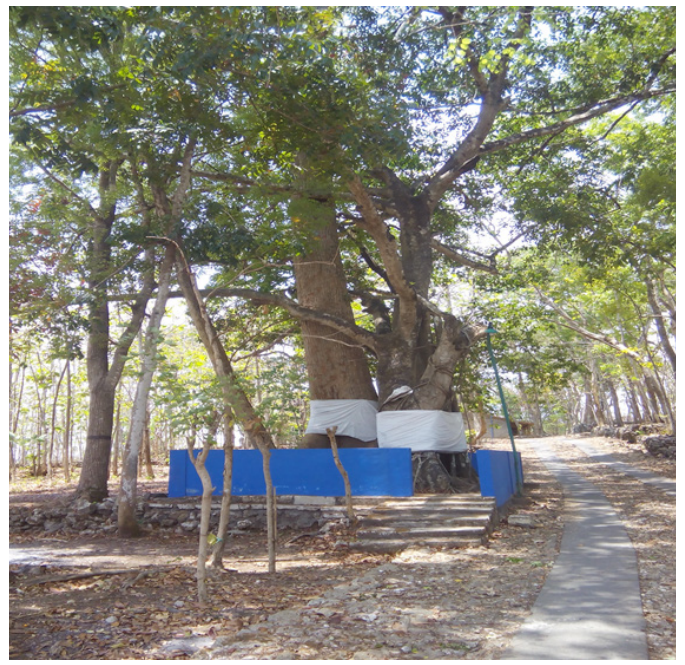

Ilustrasi 1. Dua Pohon yang Menceritakan Asal- usul Desa Tunggul dan Ungkapan dalam Panggih Manten (Sunaryo, 2018).

\section{Tradisi Lisan Setengab Verbal}

Tradisi lisan setengah verbal meliputi tradisi tentang Jathilan (Destriyanto, 2018), Makbulke Kenduri (Kristianto, 2018), Mitoni/Tingkeban (Danarti, 2018), Gumbregan (Sugiyarto, 2018), Gendruk Langen Cerita (Istiyani, 2018), Upacara Tradisional Nguras Sendhang Kali Bubar (Nugroho, 2018), dan Permainan Cublek-Cublek Suweng (Agriyati, 2018). Contohnya adalah tradisi tingkeban/mitoni saat usia kandungan 7 bulan. Dukun/ orang yang dituakan (wanita) ketika mengganti kain jarik yang dibalutkan ke tubuh ibu yang dipitoni mengucapkan "Wis pantes apa durung?" 'Sudah pantas atau belum?'. Hadirin menjawab "durung" 'belum'. Untuk jarik yang ke-7, hadirin menjawab "sampun" 'sudah' (dilaksanakan tanya jawab sampai jarik ketujuh).

\section{Tradisi Lisan Nonverbal (material)}

Tradisi lisan nonverbal meliputi tradisi tentang Batik Gedangsari (Putra, 2018), Pembuatan Tempe Dhele (Saryati, 2018), Proses Pembuatan Tempe Mlanding (Trisnawati, 2018), Legomoro (Ernawati, 2018), Kletek/Manggleng Bedoyo (Sulistiyani, 2018), Kripik Gadung (Santoso, 2018), Cemplon (Setyowati, 2018), Pilis (Tapel Dahi) (Diyanti, 2018), Pembuatan Tampah (Setyawati, 2018), Adus Banyu Gege (Dewi, 2018), Uyup-Uyup (Dewi, 2018), Batu Penunjuk Waktu (Septioriani, 2018), dan Ubarampe Tetakan (Wahyuningsih, 2018).

Batik gedangsari mempunyai corak atau motif yang khas, yaitu gambar daun dan buah pisang

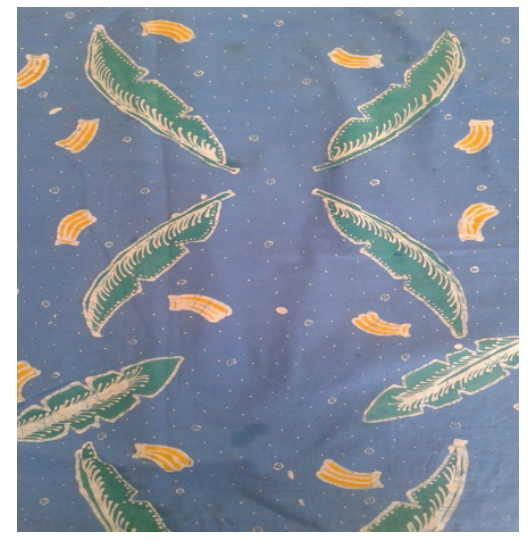

Ilustrasi 2. Motif Batik Gedangsari 
(musaceae) atau gedhang 'pisang', yang dalam bahasa Jawa senada dengan nama kecamatan Gedangsari. Contoh lainnya adalah pesan yang didapat Ibu Maryati dari neneknya yang masih diingat sampai saat ini tentang cara membuat tempe mlanding, yakni:

"Aja ngasi nglalekke apa sik was takajarke, Ti. Soale ki tempe mlandhing ki wis barang langka angel golek-golekane. Wis arang wong gawe tempe mlandhing. Selagi kowe ijik sehat lan kuat, terusna anggonku ngajari Bapakmu lan kowe gawe tempe mlandhing."

(Jangan sampai melupakan apa yang sudah saya ajarkan, Ti. Sebab tempe mlanding ini barang langka, sulit menemukannya. Sudah jarang orang membuat tempe mlanding. Selagi kamu masih sehat dan kuat, teruskanlah caraku mengajari Bapakmu dan kamu membuat tempe mlanding).

Data tradisi lisan yang telah terkumpul kemudian dapat dipetakan melalui diagram berikut.

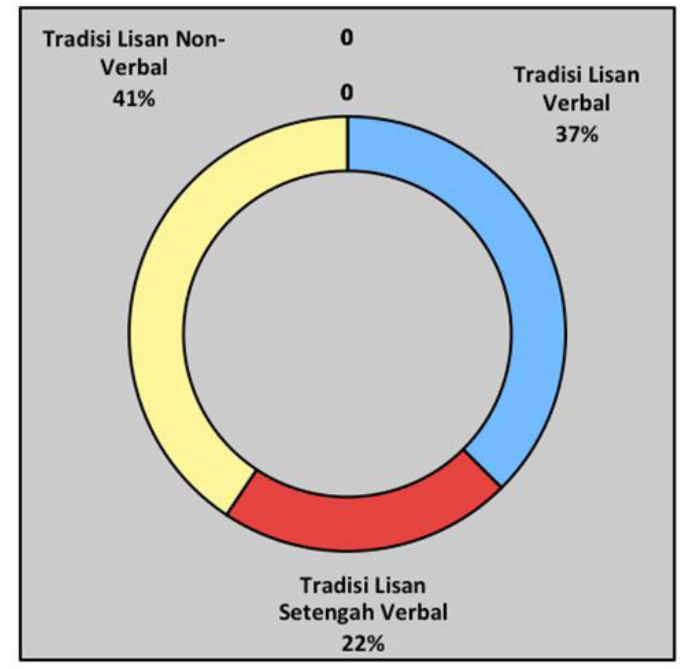

Ilustrasi 3. Diagram Pemetaan Tradisi Lisan Yogyakarta

Secara singkat, jenis tradisi lisan yang telah terkumpul meliputi pakaian cerita rakyat, legenda, mitos, upacara adat, permainan, teater/drama, adat-istiadat, arsitektur, pakaian dan perhiasan, makanan dan minuman, dan obat-obatan tradisional. Saat pelaksanaan kegiatan, banyak kendala dan tantangan yang dihadapi oleh peserta dan tim pengabdian sebagai pihak penyelenggara. Kendala teknis yang dihadapi adalah pencari data tidak mengumpulkan data sesuai waktu yang telah disepakati. Tim pengabdian yang bekerja sama dengan pemateri telah memfasilitasi peserta agar dapat berkomunikasi apabila mengalami kendala di lapangan, namun fasilitas tersebut tidak dimanfaatkan oleh peserta secara maksimal. Saat kegiatan monev pendataan tradisi lisan terdapat peserta yang mengalami kesulitan dalam mengelompokkan jenis tradisi lisan. Brunvard (dalam Suparno, 2018) mengelompokkan tradisi lisan menjadi tiga, yakni tradisi lisan verbal, tradisi lisan setengah verbal, dan tradisi lisan nonverbal (material).

Tradisi lisan verbal mempunyai bentuk seperti ungkapan tradisional (pepatah dan peribahasa), nyanyian rakyat, sajak atau puisi rakyat, dan cerita rakyat (dongeng, 
mitos, legenda, sage, dan cerita jenaka). Bentuk tradisi lisan setengah verbal adalah drama rakyat (ketoprak, ludruk, dan wayang), tarian rakyat, kepercayaan rakyat (gugon tuhon), upacara-upcara ritual (kelahiran, perkawinan, kematian), permainan rakyat, adat istiadat, dan pesta rakyat (sekaten, wetanan, dan nyale). Tradisi lisan nonverbal (material) berbentuk makanan dan minuman, peralatan dan senjata, obat-obatan, alat musik, pakaian dan perhiasan, kerajinan tangan, dan arsitektur rakyat.

Selain kesulitan saat mengelompokkan jenis tradisi lisan, peserta juga mengalami kesulitan saat menggali informasi yang ada di dalam tradisi lisan. Hal tersebut dapat terjadi karena faktor bahasa dan kebiasaan peserta. Faktor bahasa yang menjadi permasalahan adalah beberapa pertanyaan untuk narasumber menggunakan bahasa Indonesia sehingga membatasi narasumber dalam memadankan kosakata tentang kebudayaan. Faktor kebiasaan yang menjadi kendala adalah peserta tidak berinisiatif untuk membuat pertanyaan tambahan sehingga narasi yang terkumpul terbatas pada informasi umum. Selain itu, kesalahan penulisan bahasa Jawa pada narasi yang telah terkumpul juga menjadi tantangan tersendiri bagi peserta. Kendala tersebut menjadi tantangan tersendiri bagi tim pengabdian untuk menyelenggarakan Pendampingan Penulisan Naskah Tradisi Lisan Yogyakarta.

\section{Penutup}

Yogyakarta merupakan kota yang memiliki keberagaman jenis tradisi lisan. Tradisi lisan tersebut dapat dikelompokkan menjadi tiga jenis, yakni tradisi lisan verbal, tradisi lisan setengah verbal, dan tradisi lisan nonverbal (material). Tradisi lisan tersebut masih tetap terjaga di masyarakat Yogyakarta hingga kini. Sebelum tradisi lisan itu hilang, sudah sepantasnya sebagai masyarakat budaya mampu mendokumentasikannya melalui naskah tradisi lisan. Dalam menuliskan naskah tradisi lisan, ada beberapa kendala yang perlu dihadapi oleh tim pengabdian dan peserta. Kegiatan Pendampingan Naskah Tradisi Lisan Yogyakarta dapat tercapai dengan adanya peserta yang turut serta dan produk buku yang mengandung kumpulan naskah tradisi lisan di Yogyakarta. Manfaat yang telah nampak dengan adanya kegiatan pendataan dan pemetaan tradisi lisan sebelumnya adalah terciptanya draf narasi tradisi lisan berbahasa Indonesia dan bahasa Jawa. Draf narasi tradisi lisan tersebut masih belum sempurna dan memerlukan bantuan beberapa ahli untuk melengkapinya. Buku yang tercipta pada kegiatan "Penulisan Naskah Tradisi Lisan Yogyakarta" tidak terbatas pada salah satu bahasa. Hal tersebut dapat terjadi mengingat waktu pelaksanaan kegiatan serta keaktifan peserta untuk membuat naskah tradisi lisan. Setelah itu, tercetaknya buku tentang tradisi lisan Yogyakarta dapat membuka pintu para pegiat budaya untuk melakukan diskusi rutin. Diskusi tersebut berperan sebagai langkah keberlanjutan program dalam rangka mengkaji lebih dalam tentang nilai-nilai kearifan lokal pada tradisi lisan Yogyakarta.

\section{Daftar Pustaka}

Brunvard, Jan Harold (1998). The Study of American Folklor: An Introduction (4 ${ }^{\text {th }}$ Edition). New York: WW Norton \& Company.

Suparno, Antonius (2018). "Tradisi Lisan: Definisi, Fungsi, dan Pelestarian”. Materi 
Pelatihan Pendataan Tradisi Lisan. Yogyakarta: Fakultas Ilmu Budaya, Universitas Gadjah Mada.

Sulistyowati, dkk. (2018). "Tradisi Lisan di Daerah Istimewa Yogyakarta”. Laporan

Pengabdian kepada Masyarakat. Yogyakarta: Fakultas Ilmu Budaya Universitas Gadjah Mada. 